\title{
New pedagogical reality: challenges and answers
}

\author{
Yuliya Drobotenko, Natalia Makarova, and Nadezhda Chekaleva \\ Omsk State Pedagogical University, Omsk, Russia
}

\begin{abstract}
The relevance of the research is expressed in the study of the impact of changes in society on pedagogical reality and in determining the directions of its transformation. The purpose of the paper is to identify the professional challenges of the teaching profession and to substantiate the need to revise the basic functions of teaching activities. The research methods are: theoretical analysis of factors influencing the teaching profession; synthesis and interpretation of data on the characteristics of the activities of the subjects of the educational process, difficulties, and opportunities of pedagogical interaction. The result of the research is revealed in the substantiation of the provisions on advanced professional training of future teachers at the university, the formation of their pedagogical picture of the world. The conclusion about the need for future teachers to master the norms of the pedagogical ethos has been made, and the stages of this process have been provided. The scientific novelty of the research lies in the enrichment of the theory of pedagogy with knowledge about the value foundations and the content of pedagogical activity in a society of high modernity; new functions of pedagogical activity; features of the development of teaching practice. The practical significance is seen in the possibility of using the paper materials for further research; studying the processes of teaching, upbringing and development in new conditions; development of training materials for university students and students of advanced training courses.
\end{abstract}

\section{Introduction}

Today, the thesis that society has become different, that it has changed rapidly and differs from what it was 30-50 years ago (according to N. Kondratyev's theory of "long waves", the change step takes exactly that long), is not disputed. Modern society is called informational, postindustrial, continuously learning, "intellectualized" (knowledgeable society) [1]. British sociologist Anthony Giddens defines it as a society of "high modernity", which is characterized by the separation of space and time, which is expressed in the virtualization of social actions, extracting them from their usual context, free movement in the widest space-time framework [2].

In the era of high modernity, the following is growing:

- coordination of social activities (through the media, social networks, and other virtual communities), the subjects of which do not enter into direct "face-to-face" interaction with each other; 
- separation of social relations from a specific place and the appearance of their new combinations in unlimited space-time intervals (new types of friendships, partnerships, business, family relationships, when Skype, all kinds of messengers, chats, etc. are enough to maintain them);

- the process of "liberating" social institutions (family, marriage, education, religion, etc.) from their immediate social circumstances (today, it is not necessary to be in a family, within the walls of a university, in a temple-everything can be done online, indirectly);

- a change in everyday social practice, the deprivation of its traditional content and embodiment occurs (there is a change in traditional social roles, their "blurring"; there is a "departure" from actions here and now);

- eclecticism, expressed in a mixture of styles, images, ideas; in vivid subjectivity, originality, and uniqueness that cannot be repeated.

In these conditions, the problem associated with the need to answer the question of how the pedagogical reality is changing in such a society, what are its new contexts, what professional challenges the teacher should be ready for and how he/she can respond to them is actualized. It is required to understand, on the one hand, what experience and developmental features of modern children a teacher can and should take into account when organizing the process of education and upbringing, and, on the other hand, what means he/she has to improve the child's achievements and to support his/her general well-being.

The purpose of the study, the results of which are presented in this paper, is to identify the "challenges" of the teaching profession and to substantiate the need in order to revise the basic functions of teaching. The appeal to the study of this issue is also due to the fact that, despite the provisions of the main standardization documents - school standards, for the first time in the history of domestic education, legislatively defining personal results as the goal of general education, the set of functions of pedagogical activity in the professional standard of a teacher remains traditional (training, education, development). This legislative certainty about the modern functions of pedagogical activity has exacerbated discussions about their relevance to the challenges posed to the education system.

In our opinion, in conditions of extreme variability of social reality, the uncertainty of a person's life trajectories, the function of meaning-making and meaning-making together with the child comes to the fore.

\section{Materials and methods}

\subsection{Sources of information and the description of the problem}

In order to determine the "challenges" of the teaching profession and characterize the new functions of teaching activities, we have turned to the following sources: materials of expert reports and foresight projects on the development of high modern society (Foresight project "Childhood 2030", National Projects 2019-2024, Strategy for the Education Development in the Russian Federation for the Period up to 2025, "The Future of Education: A Global Agenda", "Atlas of New Professions"), futuristic essays and interviews with educational development experts Michael Barber, Katelyn Donnelly, Saad Rizvi, Michio Kaku, Dirk Helbing, and publications on contemporary childhood research (T.V. Akhtina, V.G. Bezrogov, M.R. Miroshkina, K.N. Polivanova, O.E. Smirnova, D.I. Feldstein) and analysis of the theory and practice of pedagogical activity in new sociocultural conditions (O.B. Dautova, Yu.I. Kunitskaya, E.V. Piskunova).

The above documents and publications indicate the radical changes that are already taking place and will occur with education in the near future. These changes are associated 
with intensive processes of digitization of society and, as a result, with the transformation of the traditional way of life and changes in all spheres of human life.

Experts, scholars, and practitioners agree that education should correspond to the present and understanding of education as the ability to reproduce accumulated knowledge is no longer enough. The main result of education is the ability of a person to accept changes, to work hard, and to steadfastly overcome difficulties.

According to Michio Kaku's forecasts, in the future, success will be achieved by the person who will develop abilities that are not available to robots: creativity, imaginative thinking, initiative, leadership skills, etc. [3]. Modern teachers compete not only with other teachers, trying to provide better educational results, but in conditions of high technological level, they have to compete with modern teaching technologies (distance, mobile, etc.).

French researcher B. Cornu believes that at the moment, there is no more a difficult profession than a teacher, and this can be seen from formal documents [4].

In their acclaimed essay Oceans of Innovation, Michael Barber, Katelyn Donnelly, and Saad Rizvi talk about an upcoming wave of innovation in education that will revolutionize it and transform it into an entrepreneurial industry. Developing an education in an entrepreneurial manner requires collective creativity, teamwork, and group leadership. Based on this, the solution of pedagogical problems today is teamwork [5].

Katerina Polivanova, Scientific Coordinator of the Center for Contemporary Childhood Research, points to the cardinal changes in childhood, the emergence of new problems in the upbringing of the younger generation (all sorts of addictions, infantilism, or early adulthood, excessive vulnerability, etc.), which also requires team pedagogical and psychological solutions. She emphasizes, "At the household and professional level, we increasingly recognize the significant difference between the knowledge and experience of modern children from the knowledge and experience of their mothers and fathers". For the modern child, the value of experience is higher than the value of having; sometimes, successful virtual socialization is more important than real traditional socialization; recognition of one's own uniqueness and originality is more significant than recognition in a group, team [6].

O.E. Smirnova notes a sharp decline in the imagination and creative activity of modern children, their unwillingness to occupy themselves with something, to make efforts to invent new games, to compose fairy tales, and to create their own imaginary world. They are fascinated and interested in little. The lack of their own content affects the relationships of children - they are not interested in communicating with others (peers, adults, teachers). They prefer to press a button and to wait for new ready-made entertainment [7].

Ilya Novokreshenov, Director of the Pokrovsky Kvartal School, said in an interview on the Govorit Moskva radio, "If you don't change the school, it will disappear as an institution - the children will stop going to it. Reproductive pedagogy is no longer needed by anyone. The modern child will have to live in the future of uncertainties" [8].

Thus, the analysis of the forecasts available today on the development of education, interviews and speeches of futurologists, publications of specialists in the field of pedagogy and psychology has shown that more and more new challenges to the education system are appearing and they are associated with the effects of the growing technological progress. The situation with finding answers to these challenges is more complicated. One thing is clear - the training of future teachers at the university should be forward-looking. The beginning of the professional path of the future teacher and his/her subsequent pedagogical activity depends on how the process of professional training is structured.

According to E. Husserl, it is not the world or its part that appears to a person, but the "meaning" of the world [9]. It is in the process of professional training at the university that an active search for the meanings and values of the profession, the awareness of the lifestyle conditioned by this profession is taking place. 


\subsection{Research methods}

The methodological basis of the research has been formed by the provisions of the sociocultural approach used to assess the processes of changing pedagogical reality in a society of high modernity.

Basic research methods: theoretical analysis allows revealing new contexts of growing up of modern youth; synthesis makes it possible to identify the key professional challenges of the teaching profession; interpretation contributes to the substantiation of new functions of pedagogical activity; modeling is aimed at describing changes in the professional training of future teachers at the university.

The object of the research is the modern pedagogical reality, reflecting the transformations of modern childhood. The paper presents the results of a search for an answer to the question of what are the new functions of pedagogical activity, as well as what should be the pedagogical picture of the world of a teacher working with modern children, what are his/her value orientations.

\section{Results and discussions}

The results of the theoretical analysis led to the conclusion that the pedagogical reality in a society of high modernity is work with modern children in the formats of their orientation and support in the world of large amounts of information, implicit meanings, and vague images. Today, the teacher teaches to analyze and to verify information, to critically evaluate it, and to "fill it with meaning".

Modern children grow up in conditions of rapid technology change, demonstration of ready-made solutions, proliferation of virtual practices, information overload, etc. For them, information ceases to be a valuable resource; their main skill becomes "filtering" and "discarding" unnecessary things. The ability to independently find answers to many questions in the virtual Internet space gives the younger generation a sense of adulthood, the opportunity to express themselves without outside help. The opinion of a famous blogger becomes more expert opinion for them than the opinion of a teacher or a parent. The world around us seems more hostile than the online world. This gives rise to such a phenomenon as "inner emigration", retiring into oneself, elevated to the value of focusing on their own experiences. A. Kurpatov at a business breakfast in Davos (January 2020) calls this phenomenon "digital autism", indicates that suffering is becoming the best skill [10]. Moreover, the widespread orientation towards success and recognition in society leads young people to suppress negative feelings; the widespread dissemination of ideas of positive psychology teaches the idea that a person should not have negative emotions, forms a feeling of shame for their manifestation. In fact, we are dealing with a person of the "new culture".

The systematization and synthesis of the indicated ideas show that the answer to these challenges is possible only if teachers master the methods of forming the awareness of life and acquiring the skill of its semantic content. The traditional triad (training, upbringing, development) underlying the professional standard can be successfully implemented only if the teacher is ready to organize the process of meaning-making and sensemaking. And this is an extremely individualized and personalized process.

In our opinion, the resources of successful pedagogical interaction under the conditions of the new pedagogical reality can also become taking into account the desire of modern young people to stand out, to differ from others, and their ability to quickly find a readymade solution to any issue, and their ability to use various technologies, and even the ability of clip thinking. Competent pedagogical use of these resources can help young 
people find their own life-affirming meanings and value orientations, overcome their excessive virtualization and alienation.

Certainly, these are new professional challenges for teachers. Approaching the above phenomena constructively, we would like to find an understanding of what to do and how to work with the younger generation. In addition, one more question arises: "Does the teacher himself/herself possess an established system of values and meanings?".

Firstly, in order to form such a worldview, value-semantic system, it is necessary already at the stage of study at the university to pay special attention to the general cultural training of future teachers, which develops the breadth and alternativeness of views, contributes to the formation of the ability to make choices in different life and professional situations, to critically assess the events and information received. The acquired universal knowledge and methods of action give the future teacher the opportunity, first of all, to "find himself/herself" in life and profession, and subsequently, to help the child from a huge number of options, a large amount of information to add meanings, find himself/herself.

Today, this is the meaning of fundamental training in a pedagogical university is revealed. Professional development, the study of formal requirements (professional standards, federal state educational standards, the national system of teacher growth, etc.), leading him/her to success and competitiveness, the teacher can subsequently engage in throughout and throughout his/her life [11].

Secondly, future teachers need to be taught the ethos of the teaching profession. Mastering the ethos (moral code and imperative of teacher behavior) means familiarizing future teachers with certain ethical norms and rules of professional behavior adopted in the pedagogical community; assimilation of intraprofessional values that perform normative and regulatory functions. Ethos education contributes to the development of a stable professional identity of future teachers, the formation of a sense of pride in them for the choice of a teaching profession [12].

It is this practice of mastering the meaning-making, sensemaking function of pedagogical activity that has been developing in Singapore for the last 50 years. Singapore is a leader in general education and today, it is at the top of international rankings that measure children's reading, math, and science abilities. Singapore's success is due to its close attention to the training of teachers at the university. The Singaporean higher school has united the best that is in the models of education of other countries (including the Soviet one) [13].

Proceeding from this, the preparation of the future teacher at the university should undergo serious changes. Such training is focused on the formation of understanding by future teachers of modern working conditions, the status of the profession, employment opportunities, prospects for professional growth; development of readiness for a variety of forms of interaction with modern children. The ideas of updating the professional training of future teachers at the university, in accordance with the identified challenges of modern pedagogical reality, presuppose the integration of the subject, methodological, and psychological-pedagogical components, the expansion of its humanitarian component. Moreover, the principles of integration should become the leading ones, both in setting goals and in determining the content of training, its forms and methods.

\section{Conclusion}

Based on the results of the study, it can be concluded that only a teacher with well-formed personal and professional guidelines, "immersed" in his/her profession, who has accepted its values; a person who is proud of his/her profession can respond to new professional challenges (the uncertainty of the pedagogical reality of a society of "high modernity", 
"virtual alienation" of the younger generation). We are experiencing an unprecedented rate of change in the world [14]. The teacher is at the very center of these changes: he/she experiences them, anticipates, adapts, in order to better meet the requirements of society. We are witnessing the birth of a "new profession"- the profession of a "Teacher of the $21^{\text {th }}$ century".

\section{References}

1. A.K. Kazancev, V.N. Kiselev, D.A. Rubvalter, O.V. Rudenskij, NBIC-technologies: Innovative civilization of XXI century, 384 (2012)

2. A. Giddens, Sociology (2009)

3. M. Kaku, The Future of Humanity. Penguin (2019)

4. B. Cornu, International Conference IITE-2010, 11 (2010)

5. M. Barber, K. Donnelly, S. Rizvi, Educational Studies, 4, 109 (2012)

6. K. Polivanova, Journal of Siberian Federal University. Humanities \& Social Sciences, $12(2014)$

7. A. E. Smirnov, Processes of subjectivation: theoretical and methodological aspects: monograph, 305 (2011)

8. Five tasks that pose a modern Russian school, https://mel.fm/

9. E. Husserl, Springer (2019)

10. This is the Digital Autism Epidemic, https://www.forbes.ru/

11. N.V. Chekaleva, N.S. Makarova, Yu.B. Drobotenko, I.V. Fetter, Psychological Science and Education, 23(1), 117 (2018)

12. C. Goh, THF Workshop Report 4, 9 (2016)

13. A.L. Goodwin, E.L. Low, L. Darling-Hammond, Empowered educators in Singapore: How high-performing systems shape teaching quality, 304 (2017)

14. B. Cornu, International Conference IITE-2010, 11 (2010) 